\title{
Reseña: La economía colombiana del siglo XX: Un recorrido por la historia y sus protagonistas. Carlos Caballero. Penguin Random House, 2016.
}

\author{
Edwin López Rivera \\ Candidato a doctor, Universidad de California, San Diego y \\ profesor asociado de la Universidad de Bogotá Jorge Tadeo Lozano, Colombia \\ https://orcid.org/0000-0001-5472-4010 \\ edwin.lopez@utadeo.edu.co
}

Fecha de recepción: 31 de mayo del 2018

Fecha de aceptación: 26 de junio del 2018

Disponible en línea: 27 de junio del 2018

Sugerencia de citación: López Rivera, E. (2018). Reseña. La economía colombiana del siglo XX: Un recorrido por la historia y sus protagonistas. tiempo\&economía, 5(2), 227-231, doi: https://doi.org/10.21789/24222704.1361

El siglo XX colombiano fue un periodo de profundas transformaciones que se dieron en contextos contradictorios de guerra y paz, de autoritarismo y democracia, y de proteccionismo y liberalización de los mercados. Se podría afirmar que en dicho siglo, la economía y la sociedad colombiana transitaron el camino hacia la modernidad de la mano de la producción y exportación de café y posteriormente de la industrialización. La industria colombiana creció $5,8 \%$ entre 1925 y 1928, tasa superior al 4,9\% a la cual creció la economía en el mismo periodo (Echavarría y Villamizar, 2007, p. 177). En Bogotá y Medellín aparecieron fábricas dedicadas a la producción de bienes de consumo interno como cervezas, chocolate, fósforos, jabones, textiles, etc. De la misma manera, el precio del café y sus exportaciones aumentaron al final de la década de 1910 y entre 1924 y 1928, en un contexto de evolución favorable de los términos de intercambio y aumento de la inversión extranjera con destino a la producción de otros 
productos como el petróleo y el banano. A partir de la década de 1930, el ciclo económico colombiano siguió de cerca las oscilaciones del precio del café a la par que surgió un grupo de industriales que pudieron acceder a financiamiento y bienes de capital en el exterior gracias a las condiciones favorables generadas por las exportaciones de café. Así, la modernización del país, el desarrollo económico y la política económica estuvieron fuertemente influenciados por los hombres detrás de la producción cafetera e industrial, ¿quiénes eran estas personas? ¿Cuál era su procedencia? ¿Cómo afectaron la política pública y el desarrollo económico colombiano entre 1930 y 1990 ? Todas estas preguntas las aborda Carlos Caballero, profesor de la Universidad de los Andes, en su libro La economía colombiana del siglo XX.

El argumento central de la obra es que cafeteros e industriales tuvieron una incidencia determinante en el diseño de la política económica entre 1930 y 1990 . Esta influencia tomó la forma de instrumentos de política macroeconómica como tasas de cambio múltiples, controles administrativos a las importaciones, controles de cambio, etc., los cuales favorecieron las actividades económicas de cafeteros e industriales en detrimento de otros sectores económicos como el de las exportaciones no tradicionales, el financiero y el comercio interno (p. 27). En esta obra Caballero expone la doble historia de la economía colombiana en el siglo XX y de la manera como cafeteros e industriales controlaron la política pública en función de sus propios intereses.

A lo largo de nueve capítulos, Caballero estudia la interacción de individuos y grupos de interés con el Estado y el efecto de estas interacciones en el desarrollo económico colombiano. Un ejercicio de cuantificación de términos que aparecen con mayor frecuencia en el texto muestra que la Federación Nacional de Cafeteros es nombrada 44 veces y ANDI: la Asociación Nacional de Industriales 20, lo cual pone en evidencia el carácter protagónico del café, los cafeteros e industriales en el análisis del autor y su interpretación del desarrollo colombiano en el siglo xx. El libro sigue una narrativa más o menos cronológica hasta el capítulo vil y en el capítulo vill se hace un análisis de economía política de los agentes y organizaciones que manejaron la economía desde 1930 hasta 1990. Al final del libro el autor estudia la economía colombiana entre 1991 y 2015, a la luz de la historia económica del siglo xx y los retos a los que se enfrentan los actores económicos y la economía colombiana en la actualidad.

El análisis se desarrolla en a torno tres periodos definidos: desde mediados del siglo XIX hasta 1905 (capítulo I), 1905 a 1931 (capítulos II y III), 1930 a 1991 (capítulos IV al vII) y 1991 a 2015 (capítulo IX). Luego de un convulsionado siglo XIX, se inicia la expansión cafetera a partir de 1905. Con las reformas constitucionales de la administración Reyes (1904-1909) se inició un periodo de relativa paz y estabilidad política en el que surgieron entidades claves para el desarrollo de la economía colombiana como el Banco de la República, la Superintendencia Bancaria y la Contraloría General de la República, así como el Ministerio de Hacienda y Crédito Público en 1923. De igual manera, los principales líderes cafeteros del país, entre ellos el futuro presidente Mariano Ospina, fundaron la Federación Nacional de Cafeteros en 1927, agremiación que permitiría organizar la institucionalidad cafetera y que le daría voz y poder de negociación a los cafeteros frente al gobierno. El poder económico y político ostentado por la Federación en el ámbito local fue reforzado por los acuerdos internacionales del café entre 1941 y 1989. El fin del acuerdo, la apertura económica y las reformas institucionales contenidas en la Constitución de 1991 significaron para el autor el fin de la estructura económica desarrollada desde 1905 alrededor del café y la búsqueda de un nuevo modelo de desarrollo y 
de negociación entre los actores de la política pública. Luego de la apertura económica y la crisis del café, la economía colombiana no logró diversificar su base exportadora, y en menos de 20 años se pasó de la dependencia del café a la del petróleo, como consecuencia de la rígida estructura de economía política creada antes de 1991.

La Federación no es el único gremio estudiado en el libro. Desde inicios de la década de 1940 comenzaron a crearse gremios especializados en el país, tanto en las distintas ramas de la producción agropecuaria como en actividades urbanas como el comercio y los servicios. En 1944 se fundó la ANDI y en 1946 la Federación Nacional de Comerciantes -FENALCO- cuyo activismo gremial se enfocó en la oposición a la protección arancelaria y en el reemplazo del "intervencionismo de Estado por una simple coordinación económica" (p. 70) lo cual se oponía parcialmente a los intereses de la ANDI. A pesar de lo contradictorio que pudieran parecer los intereses de cada gremio, la Sociedad de Agricultores de Colombia -SAC- propuso la creación de un estado corporativo que convocara a todos los gremios, idea consistente con los planteamientos del presidente conservador Laureano Gómez quien en 1952 buscó plasmar en normas constitucionales este modelo corporativo, pero que sería frenada por el golpe de Estado de 1953. Sin embargo, en el país ya se había desarrollado un corporativismo implícito en el manejo de la política económica que balanceó los intereses de los cafeteros con los industriales y que caracterizó el manejo económico hasta 1989 (p. 317).

La interacción entre el sector financiero y la industria es un ejemplo relevante del modelo corporativista implementado desde mediados de siglo. En 1950 se expidió un decreto que autorizó a los bancos para efectuar créditos con plazos hasta de cinco años para la industria, la construcción, los servicios públicos, sin exceder la suma de su capital pagado y sus reservas, al tiempo que se permitió a los bancos acudir al Banco de la República para redescontar esas operaciones con un amplio margen en las tasas de interés (p. 279). También se crearon entidades bancarias estatales para apoyar sectores productivos específicos (p. ej., los bancos Cafetero, Popular y Ganadero), así como corporaciones financieras que canalizaban capital nacional y extranjero hacia la financiación de la producción (p. 283). Los resultados de esta reforma financiera y del surgimiento de la banca de fomento han generado recientemente un debate historiográfico basado en el análisis de leyes y decretos que sobre esta materia se expidieron entre 1948 y 1968, y las asignaciones de crédito sectorial por parte de la banca privada, pública y el Banco Central (Brando, 2016). Mientras que el libro sugiere que la nueva estructura financiera benefició al sector industrial, conclusión que se apoya en trabajos previos del propio Caballero (1987) y el trabajo clásico de Antonio Urdinola (1976), la nueva evidencia muestra que la proporción de crédito recibido por la industria por parte de la banca privada y pública fue menor de lo que tradicionalmente ha asumido la historiografía. Igualmente, las proporciones de crédito subsidiado destinadas a la industria fueron bajas, a pesar de la fragmentaria evidencia recopilada sobre este aspecto. Finalmente, a diferencia de los bancos creados para apoyar financieramente la producción cafetera y agropecuaria, la industria nunca tuvo instituciones financieras que se ajustaran específicamente a sus necesidades de financiamiento (Brando, 2016, p. 34). Este debate y el libro mismo son muestra de que las complejas relaciones entre las organizaciones e individuos involucrados en el manejo de la política económica y la producción en el contexto del modelo corporativista de facto que operó en Colombia a mediados del siglo xx siguen siendo un terreno fértil para futuras investigaciones.

tiempo\&economía

Vol. 5 N. 2 - Julio - Diciembre del 2018 
El libro también explora la evolución de los actores de política económica a lo largo del siglo xx, argumentando que hacia finales de ese siglo los encargados de la política económica del país pasaron de ser "élites ilustradas" a "técnicos políticos" o "tecnopols". Esta es una interesante discusión que ha estado presente recientemente en los estudios sociales de la economía latinoamericana. Uno de los principales retos a los que se enfrentaron los primeros gobiernos republicanos fue el de poder contar con unos funcionarios preparados para afrontar las tareas diarias de la administración pública, reto que se extendió a lo largo del siglo xIx. Muchos de los intelectuales y funcionarios virreinales más lúcidos de las postrimerías del periodo colonial fueron fusilados durante la Reconquista, por lo cual los primeros gobiernos estuvieron conformados, principalmente, por militares y algunos civiles que en general fueron "buenos para la guerra, malos para la paz" (Contreras, 2010) con algunas notables excepciones. Esta tendencia se revirtió a mediados del siglo xIX cuando civiles educados en leyes y humanidades empezaron a ocupar cargos públicos a nivel central y en las principales ciudades del país. Ya para principios del siglo $x x$ hombres de negocios empezaron a ocupar puestos públicos tanto en el nivel ejecutivo como en la junta directiva del Banco Central y para 1990 aparecieron funcionarios con doctorados en economía y con cierto recorrido en la política y la administración pública, conocidos como "tecnopols", lo cual también sucedió en países de la región como México, Chile y Argentina. La profesionalización de la administración pública en México presenta un interesante punto de comparación. Durante la época del Porfiriato (1876-1911) surgió un grupo de funcionarios conocidos como "los científicos" fuertemente influenciados por el positivismo francés de Auguste Comte y que buscaban aplicar métodos provenientes de las ciencias sociales a la solución de problemas de la administración pública, con el fin de conducir a México por la senda de la modernización y la industrialización (Priego, 2016). Después de la Revolución Mexicana, el término volvió a aparecer durante el gobierno de Plutarco Elías Calles (1924-1934) para designar a funcionarios públicos que provenían del sector privado y que tenían un conocimiento mucho más solido en finanzas y negocios en comparación con sus antecesores decimonónicos. La influencia del positivismo en la administración pública a finales del siglo xIX y principios del xx también se puede apreciar en países como Brasil, Argentina y Chile. Aunque el libro no profundiza en estos aspectos, sí plantea pistas interesantes para avanzar en estudios sobre la formación y evolución de la burocracia y la administración pública colombiana, en especial en el capítulo vilI.

Otro aspecto interesante que explora el libro es la relación entre poder político y económico y las disparidades económicas regionales. Una de las principales conclusiones del autor es que los dirigentes provenientes de las prosperas regiones de Antioquia, viejo Caldas y Bogotá manejaron la economía entre 1930 y 1990, mediante su influencia en cargos de poder como el Ministerio de Hacienda, la Junta Directiva del Banco de la República, la dirigencia gremial, entre otros. La presencia dominante de estos dirigentes y políticos explica "el mayor desarrollo relativo de la zona central del país en contraposición con las regiones en la periferia colombiana como las costas sobre el mar Caribe y el Pacífico, el sur y la parte oriental de Colombia" (p. 367). Sin embargo, estas disparidades regionales venían desde finales del siglo XIX, así que la prominencia de los dirigentes de estas regiones estaba respaldada, precisamente, por el mayor desarrollo relativo de sus regiones de origen.

Caballero presenta en este libro una interpretación de la economía política de la política económica colombiana en el siglo xx que permite entender mejor los retos de la coyuntura 
económica actual. Es un libro escrito en una narrativa amena y clara, que además está disponible en formato digital lo cual lo hace de fácil acceso a lectores no solo en Colombia sino en el resto del mundo, ejemplo que más editoriales colombianas deberían seguir.

La gran conclusión del autor es que la interacción de los intereses de los cafeteros, industriales, y las autoridades económicas y políticas determinó el manejo cambiario, la política exterior, el manejo monetario y financiero y la política fiscal entre 1930 y 1991. A partir de 1991 la nueva Constitución, las reformas estructurales, la terminación del pacto internacional del café y el fin de la Guerra Fría transformaron para siempre los incentivos y las estrategias de los agentes económicos nacionales. La descentralización introdujo nuevos actores al proceso de definición de la política económica modificando la rígida estructura de negociación existente desde 1930. El gran reto para los encargados de la política pública en la actualidad es el de adaptarse a estas nuevas estructuras de negociación en el contexto de la globalización, el ritmo acelerado del cambio tecnológico y los desafíos que plantea el fin del conflicto armado en Colombia.

\section{Referencias}

Brando, C. A. (2016). Winners and losers in the allocation of credit during the era of import-substitution industrialisation in Colombia, 1940-1967. Ensayos sobre Política Económica, 34(79), 21-39.

Caballero, C. (1987). 50 años de economía: de la crisis del treinta a la del ochenta. Bogotá: Asociación Bancaria de Colombia.

Contreras, C. (2010). Buenos para la guerra, malos para la paz: el legado económico de la independencia en el Perú. En S. Bandieri (comp.), La historia económica y los procesos de independencia en la América hispana (pp. 269-297). Buenos Aires: Asociación Argentina de Historia Económica y Prometeo.

Echavarría, J. J. y Villamizar, M. (2007). El proceso colombiano de desindustrialización. En J. Robinson y M. Urrutia. Economía colombiana del siglo XX un análisis cuantitativo (pp. 173237). Bogotá: Fondo de Cultura Económica y Banco de la República.

Priego, N. (2016). Positivism, Science and 'The Scientists' in Porfirian Mexico: The Philosophy of Herbert Spencer in the Historiography of Mexico. Liverpool: Liverpool University Press.

Urdinola, A. (1976). El crédito de fomento y la banca comercial. En Fedesarrollo (ed.), Lecturas sobre Moneda y Banca. Bogotá: Fondo Cultural Cafetero. 